\section{ITINERÁRIOS FILOSÓFICOS DA CIÊNCIA DA INFORMAÇÃO NO BRASIL, O PIONEIRISMO DO IBICT E A PROPAGAÇÃO DAS IDEIAS '}

\author{
Lena Vania Ribeiro Pinheiro*
}

RESUMO Análise, sob a abordagem da epistemologia histórica, do surgimento, desenvolvimento e estágio atual de pesquisas fundamentadas ou com foco em Filosofia, na Ciência da Informação e seu objeto, relacionando-as a pesquisadores, fatos, eventos e influências nacionais e do exterior. $O$ mestrado em Ciência da Informação do IBICT, introdutor dos estudos filosóficos, é traçado na sua trajetória acadêmica, bem como os demais Programas, nas suas áreas de concentração e linhas de pesquisa, para verificação da presença de estudos filosóficos. A análise incluiu, ainda, as instituições e eventos que propiciaram o desenvolvimento de pesquisas na área, como a ANCIB e os ENANCIB. A pesquisa é finalizada por uma análise da influência do pensamento de Rafael Capurro na produção científica deste campo do conhecimento, evidenciada por análise de citação nos ENANCIB. Os resultados demonstram a expansão de estudos teóricos, o seu aprofundamento e, consequentemente, maior densidade teórica no estatuto científico da Ciência da Informação.

Palavras-Chave: Ciência da informação. Pesquisas teóricas na Ciência da Informação. Filosofia da Ciência da Informação. Programas de Pós-Graduação em Ciência da informação. Rafael Capurro.

\footnotetext{
* Doutora em Comunicação e Cultura pela Universidade Federal do Rio de Janeiro, Brasil. Docente permanente do Programa de Pós-Graduação em Ciência da Informação do convênio Intituto Brasileiro de Informação em Ciência e Tecnologia e Universidade Federal do Rio de Janeiro, Brasil. Bolsista de Produtividade do CNPq

E-mail: lenavania@ibict.br.
}

\section{PRIMEIROS PASSOS FILOSOFIA NO IBICT ${ }^{2}$}

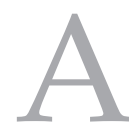

lguns anos se passaram após a criação do Mestrado em Ciência da Informação do Instituto Brasileiro de Informação Científica e Tecnológica (IBICT), em 1970, até começarem a ser introduzidos estudos filosóficos nesse campo do conhecimento.

Certamente foi condição essencial o amadurecimento teórico dos pesquisadores

I Foi apresentada uma Comunicação oral no GTI - Estudos Históricos e Cpistemológicos da Ciência da Informação, no XVIII ENANCIB. O presente texto foi revisto para publicação.

2 A citação ao IBICT, de forma isolada do convênio com a UFRJ, é motivada pelo fato de que de 1970 até 2000, o Programa de PósGraduação em Ciência da informação, inicialmente por comodato, e a partir de 1980 em convênio, ainda assim, ficou concentrado em pesquisadores do IBICT, sem a participação de professores da UFRJ. e, consequentemente, da própria área, para que o mergulho filosófico fosse concretizado. Nesse cenário, a atuação principalmente da pesquisadora do IBICT e professora do Mestrado, Maria Nélida González de Gomez, com formação em Filosofia, foi decisiva. Posteriormente a autora $^{3}$ desta comunicação passou a introduzir a Epistemologia nas suas pesquisas e estudos no Programa de Pós-Graduação em Ciência da Informação (PPGCI), ao ministrar a disciplina Perspectivas da Ciência da informação, desdobrada em duas vertentes: a histórica e a epistemológica. Mais recentemente, em 2013,

$3 \quad$ Foi possível assumir tal responsabilidade por meus estudos de Filosofia com Benedito Nunes, na graduação em Biblioteconomia, em Belém do Pará, posteriormente com Hilton Japiassu, no Mestrado em Ciência da Informação (IBICT), além do Professor Marcio Tavares do Amaral, no doutorado de Comunicação e Cultura, na UFRJ 
a aprovação de Gustavo da Silva Saldanha, em concurso para pesquisador do IBICT, com pós-graduação lato sensu (especialização, 360 horas) em Filosofia Medieval, pela Faculdade São Bento do Rio de Janeiro (FSBRJ) e de Marco Schneider, responsável no IBICT pela disciplina Ética, Epistemologia e Economia Política da Informação, da Comunicação e da Cultura,veio a consolidar as pesquisas com fundamentos filosóficos.

Estes são fatores internos, aos quais se juntam os reflexos de influências de professores convidados como Hilton Japiassu, doutor em Filosofia pela Universidade de Grenoble, na França, discípulo de Piaget e epistemólogo pioneiro da Interdisciplinaridade no Brasil.

Externamente ao IBICT, outro acontecimento importante foi a criação do Grupo de Trabalho 8 (GT-8), em 2000, sobre Epistemologia da Ciência da Informação, sob a coordenação da Professora Isis Paim, da Universidade Federal de Minas Gerais (UFMG), na Associação Nacional de Pesquisa e PósGraduação em Ciência da Informação(ANCIB), fundada em 1989. Este Grupo de Trabalho, em 2005, passou a ser o GT-1, sob a denominação de "Estudos históricos e epistemológicos de informação" e representou um estímulo às pesquisas sobre essas questões, contribuindo para a expansão das investigações em temáticas filosóficas em todo o território nacional. Mais uma vez, a presença da Professora Maria Nélida marcou esses episódios, como fundadora do GT-1 e sua Coordenadora, de 2005 a 2006, seguida da coordenação (2007-2010), da autora deste trabalho, ambas do IBICT (ANCIB,2017), já com a denominação do GT-1, ligeiramente alterada para Estudos históricos e epistemológicos da Ciência da informação.

Em âmbito internacional, a influência do filósofo Rafael Capurro no Brasil foi determinante, não somente para o aprofundamento das pesquisas filosóficas em Ciência da Informação, como pela nova vertente de estudos sobre Ética na Informação, que começou a se desenvolver em nosso País. Em Epistemologia, a pensadora portuguesa Olga Pombo, conferencista em dois ENANCIB e com a publicação de um artigo seu em revista brasileira do IBICT e UFRJ, a LIINC em Revista, veio a reforçar pesquisas de caráter filosófico na Ciência da Informação no Brasil.
Assim, considerando o aprofundamento e expansão das pesquisas de abordagem filosófica na Ciência da Informação no País, é estabelecido o seguinte objetivo desta pesquisa: descrever e analisar, sob a abordagem da epistemologia histórica, o surgimento, desenvolvimento e estágio atual de pesquisas fundamentadas ou com foco em Filosofia, na Ciência da Informação e seus objetos, relacionando-as a pesquisadores, fatos, eventos e influências nacionais e do exterior.Esta pesquisa é descritiva, a partir da literatura da área e recorre, empiricamente, à análise de áreas de concentração e linhas pesquisas dosPPGCI brasileiros, atualizando a investigação de Pinheiro (2007).

Como pesquisa descritiva, segundo Gil (2008), o objetivo é descrever as características de um determinado grupo, neste caso, a comunidade científica brasileira de Ciência da Informação, em relação às pesquisas de natureza filosófica e epistemológica.

\section{CONFIGURAÇÃO ACADÊMICA DO MESTRADO E OS ESTUDOS FILOSÓFICOS, TEÓRICOS E METODOLÓGICOS}

O mestrado em Ciência da Informação do IBICT, criado em 1970 e primeiro da América Latina e Caribe, foi uma decorrência de 15 anos de experiência na pós-graduação lato sensu do Instituto, iniciada em 1955 com o Curso de Documentação Científica (CDC), como se tornou conhecido.

Qual era o cenário brasileiro em Ciência e Tecnologia quando da criação desses cursos? Temos que iniciar lembrando que a ciência até os primórdios da República era, segundo Schwartzman (2001), "extremamente precária", mas no final do século19 já havia inúmeras instituições de ensino e pesquisa, que cresceram em número. No século seguinte, em 1940, totalizavam "10 escolas de Engenharia, 11 escolas de Medicina, 14 de Farmácia e Odontologia, 5 de Agronomia e Veterinária - além de 20 escolas de Direito, tanto públicas quanto particulares, todas inspecionadas pelo governo" (PINHEIRO; LOUREIRO, 1995). É oportuno observar que as iniciativas ocorreram sobretudo em Engenharia, Medicina e Saúde, e Agronomia, com um 
número expressivo em Ciências Humanas em uma única área, o Direito. A Ciência da Informação, portanto, como Ciência Social Aplicada que é, além de jovem cientificamente, deve ser analisada considerando essas condições científicas e tecnológicas.

Quando o PPGCI tinha mais de trinta anos de atividades, Pinheiro e Loureiro (1995) identificaram três fases:

- $\quad$ a primeira, de implantação, 1970-1982;

- $\quad$ a segunda, transitória, de 1983 a 1986; e

- a terceira, de consolidação, a partir de 1987".

Na fase inicial, o mestrado buscou a sua identidade na seleção de áreas de concentração e disciplinas e foi se modificando no conteúdo programático. Observando-se a sua trajetória acadêmica, descrita a seguir, pode-se constatar a sua vocação para estudos teóricos e sua tendência aos estudos filosóficos, que vai se acentuando no decorrer dos anos. Nas décadas que antecederam a sua implantação, as atividades de informação no Brasil estiveram concentradas em catálogos coletivos, bibliografias nacionais e serviço de intercâmbio de catalogação e informação; e praticamente não constava das políticas públicas brasileiras (PINHEIRO; LOUREIRO, 2004).

No início, o mestrado apresentava duas áreas de concentração, a saber, planejamento de sistemas e processamento da informação, e seu programa continha cinco disciplinas obrigatórias: (GONZÁLEZ DE GÓMEZ, 1982; NEVES, 1992):

i. organização de serviços de informação, posteriormente denominada organização de sistemas de informação;

ii. catalogação avançada;

iii. sistemas de classificação;

iv. técnicas de indexação e resumo; e

v. processamento de dados na documentação.

As disciplinas optativas demonstram que, apesar da ênfase no processamento da informação, havia preocupação teórica e metodológica: Programação; Epistemologia; Didática; Teoria dos conjuntos; Metodologia da pesquisa; Linguística; e Teoria da Comunicação.

Em 1976, as áreas de concentração eram três - usuários, administração de sistemas de informação e transferência da informação-, tendo no ano seguinte sido excluída a de usuários, que passou a ser disciplina.
No período de 1977 a 1979, o Mestrado era constituído por disciplinas de nivelamento, disciplinas obrigatórias comuns às áreas de concentração e disciplinas optativas, tendo as disciplinas de nivelamento sido substituídas por um ciclo preparatório. (NEVES, 1992).

Na fase posterior $(1980 / 81)$

a ênfase é nos sistemas de informação,
tanto entre as disciplinas obrigatórias
(recuperação da informação e
automação de sistemas de informação),
quanto no chamado ciclo avançado:
administração de sistemas de
informação, análise de sistemas e
avaliação de sistemas de informação.
(PINHEIRO; LOUREIRO, I995, p.49).

Ainda os mesmos autores complementam sua afirmativa: "Nesse período, as disciplinas eletivas são mais numerosas, o que parece indicar maior flexibilidade e amplitude curricular, tendência que se acentua nos anos seguintes, além da presença da Epistemologia".

$\mathrm{O}$ IBICT e, consequentemente, o mestrado, passaram por transformações políticoadministrativas, sendo a mais polêmica a transferência do Instituto para Brasília, em 1980.

Em 1983, foi assinado convênio com a UFRJ e o Mestrado foi instalado no Campus da Universidade na Praia Vermelha, o que corresponde à segunda fase, a transitória, de 1983 a 1986, quando os seus rumos institucionais ainda não estavam definitivamente estabelecidos.

O conteúdo programático do Mestrado foi passando pelas naturais mutações, algumas das quais merecem ser destacadas como o início, em 1985, da linha de pesquisa informação, cultura e sociedade, "que abre um novo espaço curricular" e passa, posteriormente, a ser área de concentração. (CNPq/IBICT-UFRJ/ECO. Comissão do Convênio, 1987)

Em 1994, importante e definitivo passo foi dado para a consolidação e expansão das atividades de ensino e pesquisa da área, com a criação do doutorado em Ciência da Informação. No período de 1992-1993, constituía uma linha de pesquisa no doutorado em Comunicação, da UFRJ, sob a liderança do Professor Aldo Barreto. Ao mesmo tempo, o PPGCI é fortalecido no âmbito do próprio IBICT, com a implantação do Departamento de Ensino e Pesquisa, que antes existira e fora extinto. 
As áreas de concentração do Mestrado nessa fase são: processamento da informação, estrutura e fluxo de informação, informação cultura e sociedade e, no doutorado, Informação cultura e sociedade, Informação, tecnologia e sociedade e Epistemologia, interdisciplinaridade e Ciência da Informação (1994), nas quais se pode perceber a relevância atribuída à Epistemologia.

Nos anos 2000, o PPGCI passou por outro período de transição quando não foi renovado o convênio com a UFRJ, por decisão do então Diretor do IBICT ${ }^{4}$, e foi assinado convênio com a UFF, no período de 2003 a 2008. No final de 2008, o PPGCI retorna ao convênio com a UFRJ, inicialmente com a Faculdade de Administração e Ciências Contábeis (FACC) e, a partir de 2012, com a Escola de Comunicação(ECO), voltando à mesma situação institucional de 1983. (PPGCI/ IBICT ECO/UFRJ-,2017) ${ }^{5}$

As vinculações administrativas e acadêmicas do Programa são aqui mencionadas porque afetam a constituição do corpo docente e mesmo a configuração do Programa, podendo quebrar a continuidade de linhas de pesquisa e disciplinas. Ainda assim, o PPGCI não abandonou a sua vocação teórica e filosófica, o que pode ser hoje verificado pela área de concentração, linhas de pesquisa e disciplinas, analisadas a seguir e indicadas no Quadro 1.

Atualmente, o PPGCI é constituído por uma área de concentração, Informação e Mediações Sociais e Tecnológicas para o Conhecimento, que abrange "questões de interdisciplinaridade", e duas linhas de pesquisa. A linha de pesquisa 1 desenvolve-se em torno de Comunicação, Organização e Gestão de Informação e de Conhecimento, e inclui "estudos históricos e epistemológicos da Ciência da Informação e metodologias das Ciências Sociais aplicadas". A linha de pesquisa 2 é denominada Configurações sócio culturais, políticas e econômicas da informação, na qual os estudos de ética fazem parte (PPGCI/IBICTECO/UFRJ, 2017). Para a evolução e avanços das pesquisas, em quantidade e qualidade, são essenciais políticas públicas de fomento e instituições que as viabilizem, o que será abordado na seção a seguir.

\footnotetext{
4 Nessa ocasião, era Diretor do IBICT Nilson Lage, ex-professor da Escola de Comunicação (ECO), da UFRJ.

5 Disponível em: http://www.ppgci.ufrj.br/apresentacao/. Acesso em:25 ul.2017
}

\section{FATOS DA POLÍTICA CIENTÍFICA NACIONAL, INSTITUCIONAL E ACADÊMICA QUE IMPULSIONARAM AS PESQUISAS FILOSÓFICAS}

Sobre as políticas públicas nacionais para o desenvolvimento de pesquisas e pós-graduação em Ciência da informação, dois marcos são ressaltados, entre outros, por Oliveira (1998) na sua tese de doutorado: a criação do Conselho Nacional de Desenvolvimento Científico e Tecnológico (CNPq) e da Coordenação de Aperfeiçoamento de Pessoal do Nível Superior (CAPES), em 1951.

Desde a década de 1970, a Ciência da Informação já fazia parte do fomento do CNPq, como subárea da Comunicação e denominada Ciências da Informação, no plural. Na década seguinte, passa a área do conhecimento, como Ciência da Informação, juntamente com a Biblioteconomia e a Arquivologia. A partir de 1984, é criada a grande área Ciências Sociais Aplicadas e a Ciência da Informaçãoconstitui uma área do conhecimento. (SOUZA; STUMPF, 2009)

Um fato relevante é a criação da ANCIB, já mencionada no início deste trabalho, cujo objetivo "é acompanhar e estimular as atividades de ensino de pós-graduação e de pesquisa em Ciência da Informação no Brasil" (ANCIB, 2017). A subsequente institucionalização do Encontro Nacional de Pesquisa em Ciência da Informação (ENANCIB), como ação da ANCIB, a partir de 1994, completou um cenário propício e estimulante às pesquisas na área. ${ }^{6}$

Antes dos ENANCIB,atividades de pesquisa eram apresentadas principalmente durante os Encontros (1980-1994) realizados pelos programas de pós-graduação existentes que, por sua vez, preenchem, parcialmente, o vazio deixado pelas Reuniões Brasileiras de Ciência da Informação, realizadas com muito sucesso, em 1975 e 1979, promovidas pelo IBICT. No entanto, essas Reuniões contavam com a participação de cientistas de inúmeras áreas, diferentemente dos ENANCIB, que estão

\footnotetext{
6 Disponível em:http://enancib.ibict.br/index.php/enancib/index/ schedConfs/archive. Acesso em:25jul.20l7.
} 
centrados nos pesquisadores e professores dos PPGCI brasileiros.

No XII Encontro dos Cursos de PósGraduação em Ciência da Informação e Biblioteconomia, de 1992, realizado no âmbito da ANCIB, foi sugerido por Marlene de Oliveira, participante do Encontro, que a própria ANCIB promovesse regularmente um evento para apresentação de pesquisas e promoção de debates sobre as questões científicas da área. (FREIRE; ALVARES, 2013).

A ANCIB, fundada em 1989, conforme mencionado no início deste trabalho, assumiu a responsabilidade da realização do evento sugerido, denominado Encontro Nacional de Pesquisa e Pós-Graduação em Ciência da Informação, o primeiro em 1994, na Universidade Federal de Minas Gerais.

Entre os atualmente 11 Grupos de Trabalho da ANCIB, um é dedicado especificamente aos Estudos Históricos e Epistemológicos da Ciência da informação, o GT-1, conforme mencionado anteriormente. Em 2014, no XV ENANCIB foi apresentado estudo sobre o GT-1 realizado pela Professora Lídia de Freitas, da UFF, a partir de dados coletados na base de dados BENANCIB, desenvolvida por esta professora e alunos. Foram levantadas 232 comunicações até 2013, apresentadas nos 14 anos de atividades do GT-1 e constatado que as pesquisadoras mais citadas foram Maria Nélida González de Gómez e a autora desta comunicação, 207 vezes em 122 trabalhos, o que ensejou uma homenagem a ambas, com a entrega de uma placa comemorativa. ${ }^{7}$

\section{INDICADORES DA EXPANSÃO DAS PESQUISAS TEÓRICAS E FILOSÓFICAS NA CIÊNCIA DA INFORMAÇÃO}

Entre os diferentes indicadores que podem refletir a expansão das pesquisas teóricas e filosóficas na Ciência da Informação, a opção foi levantar os Programas de Pós-Graduação, uma vez que, pela análise de suas áreas de concentração e linhas de pesquisa, pode ser verificado o crescimento de pesquisa dessa natureza. Como em 2007 a autora deste trabalho apresentou, no ENANCIB de 2007, o cenário da pós-graduação em Ciência da Informação no Brasil, os resultados serviram de parâmetro para a pesquisa atual. Na ocasião, eram nove (9) programas, sendo cinco (5) com mestrado e doutorado e quatro (4) apenas mestrado (PINHEIRO, 2007).

Nas áreas de concentração, as questões são mais amplas e informação estava presente em quatro áreas, juntamente com o conhecimento, o que pode refletir uma tendência ao paradigma cognitivo. Com a mesma incidência aparece Gestão da Informação, em quatro áreas.

Quanto às linhas de pesquisa, predominou a Gestão da Informação (UFMG, PUCCAMP, UNB e UFBA), seguida da amplitude de abordagem, a partir de informação: Informação, Conhecimento e sociedade (IBICT-UFF); Informação, cultura e sociedade (UFMG); e Informação e Contexto sócio - econômicos (UFBA).

$\mathrm{Na}$ presente pesquisa, no levantamento com este mesmo objetivo, a primeira observação foi o aumento do número de Programas, passados 13 anos. Hoje totalizam 23 cursos, sendo 4 de mestrado e 11 de mestrado e doutorado, além de oito (8) mestrados profissionais. A opção metodológica foi a análise dos 11 Programas com mestrado e doutorado, porque, por serem mais antigos, podem ser considerados consolidados. Portanto, foram excluídos os cursos somente de mestrado e de mestrado profissional. No Quadro 1 são apresentadosos resultados da análise de áreas de concentração e linhas de pesquisa desses Programas.

\footnotetext{
7 As informações sobre essa comemoração estão na programação detalhada do GT-I, no ponto de acesso Especial: O GT-I nos 25 anos da ANCIB e os 60 anos do IBICT. Disponível em: http://enancib20I4.eci. ufmg.br/programacao/programacao-detalhada-gt I Acesso em: 3 ago. 2017.
}

Inf. \& Soc.:Est., João Pessoa, v.27, n.3, p. 121-130, set./ dez. 2017 
Quadro 1 - Programas de pós-graduação, áreas de concentração e linhas de pesquisa, $2017^{8}$

\begin{tabular}{|c|c|c|c|}
\hline Instituições & Programa de pós-graduação & Área de concentração & Linhas de pesquisa \\
\hline 1. UFBA & Ciência da Informação & $\begin{array}{l}\text { Informação e Conhecimento na Socie- } \\
\text { dade Contemporânea }\end{array}$ & $\begin{array}{l}\text { 1. Políticas e Tecnologias da } \\
\text { Informação } \\
\text { 2. Produção, Circulação e } \\
\text { Mediação da Informação }\end{array}$ \\
\hline 2. UFF & Ciência da Informação & $\begin{array}{l}\text { Dimensões Contemporâneas da Infor- } \\
\text { mação e do Conhecimento }\end{array}$ & $\begin{array}{l}\text { 1. Informação, Cultura e } \\
\text { Sociedade } \\
\text { 2. Fluxos e Mediações Sócio- } \\
\text { Técnicas da Informação }\end{array}$ \\
\hline 3. UFMG & $\begin{array}{l}\text { Gestão \& Organização do } \\
\text { Conhecimento }\end{array}$ & Representação do Conhecimento & $\begin{array}{l}\text { 1. Arquitetura \& Organização do } \\
\text { Conhecimento (AOC) } \\
\text { 2. Gestão \& Tecnologia (GET) }\end{array}$ \\
\hline 4. UFMG & Ciência da Informação & Informação, Mediações e Cultura & $\begin{array}{l}\text { 1. Memória Social, Patrimônio e } \\
\text { Produção do Conhecimento } \\
\text { 2. Políticas Públicas e } \\
\text { Organização da Informação } \\
\text { 3. Usuários, Gestão do } \\
\text { Conhecimento e Práticas } \\
\text { Informacionais }\end{array}$ \\
\hline 5. UFPB & Ciência da Informação & Informação, Conhecimento e Sociedade & $\begin{array}{l}\text { 1. Informação, Memória e } \\
\text { Sociedade } \\
\text { 2. Organização, Acesso e Uso da } \\
\text { Informação } \\
\text { 3. Ética, Gestão e Políticas de } \\
\text { Informação }\end{array}$ \\
\hline 6. UFPE & Ciência da Informação & Informação, Memória e Tecnologia & $\begin{array}{l}\text { 1. Memória da Informação } \\
\text { Científica e Tecnológica } \\
\text { 2. Comunicação e Visualização da } \\
\text { Memória }\end{array}$ \\
\hline 7. UFRJ IBICT & Ciência da Informação & $\begin{array}{l}\text { Informação e Mediações Sociais e Tec- } \\
\text { nológicas para o Conhecimento }\end{array}$ & $\begin{array}{l}\text { 1. Comunicação, Organização e } \\
\text { Gestão da Informação e do } \\
\text { Conhecimento } \\
\text { 2. Configurações socioculturais, } \\
\text { políticas e econômicas da } \\
\text { informação }\end{array}$ \\
\hline 8. UFSC & Ciência da Informação & Gestão da Informação & $\begin{array}{l}\text { 1. Organização, Representação e } \\
\text { Mediação da Informação e do } \\
\text { Conhecimento } \\
\text { 2. Organização e Preservação do } \\
\text { Conhecimento }\end{array}$ \\
\hline 9. UNB & Ciência da Informação & Gestão da Informação & $\begin{array}{l}\text { 1. Organização da Informação } \\
\text { 2. Comunicação e Mediação da } \\
\text { Informação }\end{array}$ \\
\hline 10. UNESP & Ciência da Informação & $\begin{array}{l}\text { Informação, Tecnologia e Conheci- } \\
\text { mento }\end{array}$ & $\begin{array}{l}\text { 1. Informação, Tecnologia e } \\
\text { Conhecimento } \\
\text { 2. Produção e Organização da } \\
\text { Informação } \\
\text { 3. Gestão, Mediação e Uso da } \\
\text { Informação }\end{array}$ \\
\hline 11. USP & Ciência da Informação & Cultura e Informação & $\begin{array}{l}\text { 1. Apropriação Social da } \\
\text { Informação } \\
\text { 2. Gestão de Dispositivos de } \\
\text { Informação } \\
\text { 3. Organização da Informação e do } \\
\text { Conhecimento }\end{array}$ \\
\hline
\end{tabular}

Fonte: Dados da pesquisa

8 Agradeço à funcionária do IBICT, Vera Lucia Cruz, o levantamento de informações atuais sobre os Programas de Pós-Graduação em Ciência da Informação brasileiros. 
Pode-se observar que, na denominação das áreas de concentração e linhas de pesquisa não aparecem, explicitamente, Filosofia ou Epistemologia da Ciência da Informação ou
Filosofia da Informação, embora possam constar nas disciplinas, daí a sua análise, considerando as informações disponíveis em cada portal de Programa, conforme mostradas no Quadro 2.

Quadro 2 - Programas de Ciência da Informação com disciplinas de natureza filosófica

\begin{tabular}{|c|l|}
\hline $\begin{array}{c}\text { PROGRAMAS DE PÓS- } \\
\text { GRADUAÇÃO EM CI }\end{array}$ & \multicolumn{1}{c|}{ DISCIPLINAS } \\
\hline IBICT/UFRJ & $\begin{array}{l}\text { 1.Perspectivas em Ciência da Informação } \\
\text { 2.Seminários Interdisciplinares em Informação e Conhecimento } \\
\text { 3.Epistemologia da Ciência da Informação } \\
\text { 4.Teoria e História da Informação }\end{array}$ \\
\hline UFBA & Fundamentos Históricos e Epistemológicos da Ciência da Informação \\
\hline UFF & Ciência da Informação: trajetos e horizontes epistemológicos \\
\hline UFMG & Fundamentos da Ciência da Informação \\
\hline UFPB & Fundamentos Teóricos da Ciência da Informação \\
\hline UFPE & Fundamentos da Ciência da Informação \\
\hline UFSC & Epistemologia da Ciência da Informação \\
\hline UnB & Fundamentos da Ciência da Informação \\
\hline UNESP & Fundamentos da Teoria da Informação \\
\hline
\end{tabular}

Fonte: Dados da pesquisa

As disciplinas elencadas mostram que pelo menos uma de caráter filosófico ou epistemológico é oferecida em nove (9) dos 11 Programas analisados, excetuando a USP e o Curso de Gestão \& Organização do Conhecimento da UFMG. De um modo geral, aparece pelo menos uma disciplina relacionada a essas questões, a maioria sobre Fundamentos da Ciência da Informação e um de Fundamentos da Teoria da Informação, da UNESP, que pressupõe discussão teórica sobre informação, a partir dessa teoria. Em dois Programas, da UFF e da UFBA são incluídas, explicitamente, disciplinas de caráter epistemológico. Destaca-se o PPGCI, do IBICT-UFRJ, com quatro disciplinas de teor filosófico, abordando Epistemologia e interdisciplinaridade da Ciência da Informação e uma especifica para seu objeto, a informação (Teoria e Historia da Informação).

\section{PRESENÇA E INFLUÊNCIA DE RAFAEL CAPURRO EM PESQUISAS FILOSÓFICAS NA CIÊNCIA DA INFORMAÇÃO}

Nas comemorações dos 70 anos do filósofo Rafael Capurro, em 2014, foi planejado na Alemanha um livro em que pesquisadores de diferentes países escrevessem sobre a obra do pensador. Quatro brasileiros foram convidados, dos quais três do IBICT: Gustavo Saldanha, Marco Schneider e a autora desta comunicação, todos os três dedicados a estudos teóricos, filosóficos, epistemológicos, inclusive Ética na Informação. A quarta professora brasileira, também autora do livro é Plácida Leopoldina V. A. de Costa Santos, da UNESP, que apresentou pesquisa sobre o ensino da Ciência 
da Informação no Brasil, juntamente com Chaim Zins, da Universidade de Haifa, em Jerusalém. O título do capítulo elaborado pela autora desta comunicação foi: "Reflectionson Rafael Capurro's Thoughts in Education and Research of Information Science in Brazil". Foi uma oportunidade ímpar de verificarmos a extensão da repercussão das ideias de Capurroem nosso País, e o quanto a Ciência da informação aqui gerada deve ao grande teórico (PINHEIRO, 2015).

Acompanhamos a maioria das ações acadêmicas e científicas de Capurro no Brasil, e sabemos que estudiosos brasileiros da Ciência da Informação tem se dedicado a pesquisar especificamente esse teórico e suas idéias, bem como elaboraram traduções de seus artigos para publicação em periódicos brasileiros. No estudo empírico, com o objetivo de "medir" essa influência, a opção metodológica foi a análise de citações para o que foi fundamental a base de dados BENANCIB, mencionada anteriormente.

Nessa pesquisa, na vasta e densa produção científica de Rafael Capurro, foram privilegiados os conceitos de informação, os paradigmas da informação (físico, cognitivo e social), a Angel ética e as questões sobre ética na Informação.

O primeiro resultado mostra o quanto essa influência foi crescendo, começando em 2003 com uma (1) citação apenas, em 2008 já são 16 e no ano de 2013, 30 citações.

O principal resultado, sobre as citações, é mostrado na Figura 1.

Figura 1 - Número de publicações de Capurro citadas por GT da ANCIB.

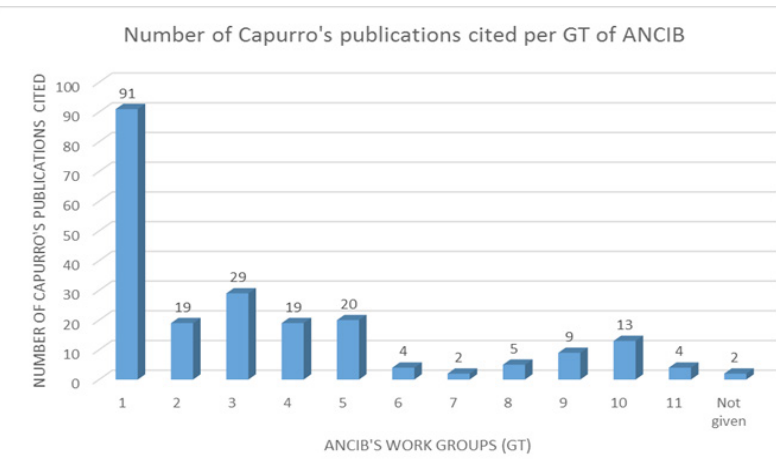

Fonte: PINHEIRO, 2015
O surpreendente é a presença de Capurro em todos os Grupos de Trabalho da ANCIB, muito mais acentuada no GT-1, totalizando 91 citações, evidentemente, por sua temática histórica e epistemológica.

Como as comunicações no ENANCIB são fruto de pesquisa, entre as quais as oriundas de teses, o pensamento do filósofo pode ter sido adotado para composição do quadro teórico. No entanto, não deixa de ser relevante que os fundamentos teóricos, qualquer que seja a questão, tenham si do elaborados com base no pensamento de Capurro, para o que deve ter contribuído o seu artigo com Hjorland, sobre informação, objeto de estudo da Ciência da Informação, seja por si só ou como regime, ações ou mediações, entre outros.

É relevante retomarmos às linhas de pesquisa, neste momento relacionadas à influência de Capurro, Ética na Informação e Filosofia da Informação, temáticas privilegiadas por Capurro e pouco estudadas até 2007, quando apenas uma Universidade, a Universidade Federal da Paraíba (UFPB), oferecia uma linha de pesquisa em Ética, Gestão e Política de informação, abrangendo teorias, metodologias e tecnologias voltadas à ética e responsabilidade social, à gestão da informação e do conhecimento, às políticas de informação e às redes sociais organizacionais" (UFPB. Linhas de pesquisa, 2017).

Foi constatada,na pesquisa atual, ainda, a inclusão de Ética na linha de pesquisa do PPGCI, do IBICT e UFRJ: "Configurações socioculturais, políticas e econômicas da informação", assim descrita: "Estudos de ética e política de informação e das tecnologias da informação e comunicação na sociedade contemporânea; regime de informação. Interfaces da informação com a ética e a sustentabilidade ambiental no mundo contemporâneo [...]". (PPGCI/IBICTECO/UFRJ, 2015).

O fato de dois programas de Pósgraduação abrangerem Etica na Informação pode estar relacionado à participação de Rafael Capurro em eventos promovidos por esses Programas, como o I Simpósio Brasileiro de Ética da Informação, realizado pela UFPB,em março de 2010, no qual foi conferencista. No entanto, é oportuno lembrar que os estudos de Ética na informação na UFPB já existiam anteriormente. 
Já no IBICT, Capurro esteve por duas vezes como professor visitante, quando ministrou aulas, proferiu palestras, participou de eventos etc., nos anos de 2010 e de 2014. Por outo lado, o Professor Capurro também exerceu atividades de pesquisa e ensino na UFMG, na Universidade Estadual Paulista Júlio de Mesquita Filho (UNESP) e Universidade de São Paulo (USP) e não foi observada, nessas universidades, a introdução de discussão filosófica em torno de Informação e de Ética na informação, nas respectivas áreas de concentração e linhas de pesquisa de seus PPGCI.

\section{REFLEXÕES FINAIS}

Por reconhecimento de que um campo do conhecimento, para ser verdadeiramente uma ciência, depende de seus pilares teóricos, esta pesquisa foi realizada com o objetivo de verificar o estágio cientifico da Ciência da Informação no Brasil e chegou a resultados animadores. Embora não tenham sido analisados, especificamente, conceitos, princípios, teorias, metodologias e leis, a existência de disciplinas filosóficas, epistemológicas e mesmo de fundamentos da área pressupõem a inclusão desses aspectos no seu conteúdo, uma vez que constituem parte essencial dessas abordagens.Entre os Programas de Pós-Graduação em Ciência da informação, a maioria demonstra interesse nos estudos filosóficos, incluindo pelo menos uma disciplina desse teor. Entres esses programas, o PPGCI do IBICT e UFRJ se destaca por maior número de disciplinas de natureza filosófica e epistemológica, abrangendo questões de interdisciplinaridade, em um total de quatro (4).

Por sua vez, pesquisadores e professores têm empreendido, de fato, pesquisas teóricas no Brasil, com enfoques filosóficos e epistemológicos, como ficou evidenciado na análise de disciplinas e de citações a Rafael Capurro, que se faz presente em todos os Grupos de Trabalho da ANCIB. Tratando-se de um filósofo de primeira grandeza, conhecido e reconhecido internacionalmente, estudos sobre o seu pensamento e idéias são expressivos indicadores.Por outro lado, organizações como a ANCIB e eventos da natureza dos ENANCIB têm representado um cenário propício ao desenvolvimento dessas pesquisas e, portanto, a avanços teóricos na área.

Outros indicadores, como Grupos de Pesquisa e projetos de pesquisa em Ciência da Informação apoiados pelo $\mathrm{CNPq}$ poderiam fortalecer os resultados desta pesquisa, o que pode ser objeto de estudos posteriores.

Se, conforme reconhecemos nos início destas reflexões, a constituição científica de uma área repousa nos seus fundamentos teóricos, e a presente pesquisa constatou a presença de pesquisas dessa natureza em todos os aspectos aqui escritos e analisados, a Ciência da Informação no Brasil caminha, cada vez mais, para solidez do seu estatuto científico.

Artigo recebido em 26/10/2016 e aceito para publicação em 15/I 1/2017

\section{PHILOSOPHICAL ITINERARIES OF INFORMATION SCIENCE IN BRAZIL, THE PIONEERING OF IBICT AND THE PROPAGATION OF IDEAS}

ABSTRACT Analysis, under the approach of historical epistemology, of the emergence, development and current stage of research based or focused on Philosophy, Information Science and it object, relating them to researchers, facts, events and national and foreign influences. The Master in Information Science at IBICT, introducer of the philosophical studies is traced in its academic trajectory, as well as those of the other Programs, in their areas of concentration and lines of research, to verify the presence of philosophical studies. The analysis also included the institutions and events that led to the development of research in the area, such as ANCIB and ENANCIB. The research is completed by an analysis of the influence of Rafael Capurro's thinking on the scientific production of the area evidenced by the citation analysis in the ENANCIB. Results demonstrate the expansion of theoretical studies, their deepening and, consequently, greater theoretical density to the scientific status of Information Science.

Keywords: $\quad$ Information Science. Information Science Philosophy. Post-Graduation Programs in Information Science. Theoretical Research in Information Science.Rafael Capurro. 


\section{REFERÊNCIAS}

CNPq/IBICT -UFRJ/ECO. Comissão do convênio. A Pós-Graduação em Ciência da Informação na UFRJ. Ciência da Informação, v. 16, n. 2, p. 113-124, jul./dez. 1987. Disponível em: <http://revista.ibict.br/ciinf/issue/view/31/ showToc>. Acesso em: 27 jul. 2017

FREIRE, Isa Maria; ALVARES, Lillian. 25 anos da ANCIB: relatos sobre sua história e contribuição para a área de Ciência da Informação no Brasil. Tendências da Pesquisa Brasileira em Ciência da informação, v.6, n.2, jul./dez. 2013. Disponível em:< http://basessibi.c3sl.ufpr.br/ brapci/ index.php/article/view/0000016096/ 1bf983795b7a3454f58d019ff934ee64>. Acesso em: 25 jul. 2017

GIL, Antonio Carlos. Métodos e técnicas de pesquisa social. 6. ed. São Paulo: Atlas, 2008.

GONZÁLEZ DE GOMÉZ, Maria Nélida. A configuração temática de Ciência da Informação do Instituto Brasileiro de Informação em Ciência e Tecnologia.1982. Diss. (Mestrado em Ciência da Informação) - UFRJ/ECO,CNPq/ IBICT, Rio de Janeiro, 1982.

MEC. CAPES. Progrmas de Pós-Graduação em Ciência da Informação credenciados. Disponível em: <

https://sucupira.capes.gov.br/sucupira/ public/consultas / coleta / programa / quantitativos/quantitativoAreaConhecimento. jsf?areaAvaliacao $=31>$. Acesso em: 13 maio 2017

NEVES, Teodora Marly Gomes de. História e temática do Curso de mestrado em Ciência da Informação do Instituto Brasileiro de Informação em Ciência e Tecnologia. 1992.Diss. (Mestrado em Ciência da Informação) -, UFRJ/ ECO, CNPq/ IBICT, Rio de Janeiro, 1992.

OLIVEIRA, Marlene. A investigação científica na Ciência da Informação:análise da pesquisa financiadas pelo CNPq. Orientadora: Suzana Pinheiro Machado Mueller. 1998. Tese .( (Doutorado em Ciência da informação).UNB, Brasília, 1998.

PINHEIRO, Lena Vania Ribeiro. Cenário da pós-graduação em Ciência da informação no Brasil, influências e tendências. In: -ENCONTRO NACIONAL DE PESQUISA EM CIÊNCIA DA
INFORMAÇÃO - ENANCIB, 8.,2007, Salvador. In: Anais... Salvador: Associação Nacional de Pesquisa e Pós-Graduação em Ciência da Informação; UFBa 2007.

PINHEIRO, Lena Vania Ribeiro. Infra-estrutura da pesquisa em Ciência da informação no Brasil. In: ENCONTRO NACIONAL DA ASSOCIAÇÃO NACIONAL DE PESQUISA E PÓS-GRADUAÇÃO EM CIÊNCIA DA INFORMAÇÃO - ENANCIB, 4, 2000, Brasília.In:.. Brasília: ANCIB, 2000. Disponível em CD-ROM.

PINHEIRO, L. V. R. Reflections on Rafael Capurro's thoughts in education and research of Information Science in Brazil. In: Mathew Kelly; Jared Bielby. (Org.). Information cultures in the digital age; a festscrift in honor of Rafael Capurro.. 1ed.Wiesbaden: Springer, 2016, v. 1, p. 413-426.

PINHEIRO, Lena Vania Ribeiro ; LOUREIRO, José Mauro Matheus. Traçados e limites da Ciência da Informação. Ciência da Informação, Brasília, v.24, n.1, p.42-53,jan./jul.1995. Disponível em: <http://www.ibict.br/ cienciadainfomacao .Acesso $>$. Acesso em: 21 jun. 2017

POMBO, Olga. Interdisciplinaridade e integração dos saberes. LIINC em Revista, v.1, n.1, p.3-15, mar., 2005. Disponível em:< http://revista.ibict. br/liinc/index.php/liinc>. Acesso em: 23 jun. 2017

PPGCI/ IBICT-ECO/UfRJ. Programa de Pós Graduação em Ciência da Informação, 2017. Disponível em: <http://www.ppgci.ufrj.br/ apresentacao/>. Acesso em: 3 ago.2017.

SCHARTZMAN, Simon. Um espaço para a ciência: a formação da comunidade científica no Brasil. Brasília: Ministério da Ciência e Tecnologia, Centro de Estudos Estratégicos, 2001.

SOUZA, Rosali Fernandez de;STUMPF, Ida Regina Chitto.Ciência da Informação como área do conhecimento: abordagem no contexto da pesquisa e da Pós-Graduação no Brasil. Perspectivas em Ciência daInformação, . 2009, v..14, n. esp., p.41-58, 2009. Disponível em: <http://dx.doi.org/10.1590/S141399362009000400004>. Acesso em: 30 jul. 2017.

UFPb. Linhas de pesquisa. Disponível em: <http://www.ccsa.ufpb.br/ppgci/contents/ paginas/ppgci-ufpb/linhas-de-pesquisa>. Acesso em: 4 ago.2017. 